\title{
Computer-Aided Test Flow in Core-Based Design
}

\author{
V. A. Zivkovic, R. J. W. T. Tangelder and H. G. Kerkhoff
}

\begin{abstract}
This paper copes with the test-pattern generation and fault coverage determingtion in the core-based design. 'The basic core-test strategy that one has to apply in the coreJinited design is stated in this work. A Computer-Aided Test (CAT) flow is proposed resulting in accurate fault coverage of embelded cores. The CAT now is applied to a few cores within the Philips Core Test Pilot IC project.
\end{abstract}

\section{INTRODUCTION}

The development of semiconductor technology in recent years and the strong expectation, that this trend will futhermore continue, cuable the design of complete systems-on-chip (SOC). In order to use the design resourcos in an efficient manner while building such systems, a new design style, Core-based design, has been established. The main point of the Corembased design style is the integration of reusable, parametrized blocks, so called cores, Cores, also described as IP's (Intellectual Property), modules or blocks, can appear in hard (layoul), firm (netlist) or soft (RTL-lovel) form. Core-based design has led the IC design community into lwo groups: corte providers and core users. One of the challenges facing design and test engineers in this kind of environment is the elaboration of a comprebensive test strategy. The importance of manufacturing tests for these devices is very obvious if one has their astonishing complexily in mind. Therefore, special attention has to be paid to design-fortestability (DfT) circuitries and test pattern generation of such complex circuits. An efficient high-coverage test approach is crucial to ensure that only good products will he shipped to the customers at rensonable test costs.

There have been a number of academical and industrial approaches to tackle this problem such as the ones described in [1-5], ete. In order to establish the worldwide standardisation regarding the core-test, a number of companies discuss IEEE P1500 [6].

This paper is organised as follows. The second section outlines briefly the core-based test described within the Philips Core Test Action Group - CTAG [7]. Next, the basic llow of the test pattern generation in an embedded core environment is explained from the point of view of the

V. A. Zjvkovic, R. J. W. T. Tangelder and H. G. Kerkhoff are with the MESA+ Research Institute, The University of Twente, P.O. Box 217, 7500 AE Enschede, The Netherlands, E-mail: V.Zivkovic(âtelutwente,nl core provider. The determination of accurate fault coverage in this environment is also included in the third section. The core-based test flow has been applied to a Philjps pilot IC and the results are presented in section IV. Section V concludes the paper.

\section{CORE TEST}

The principal motive for core-based design and test is the time-to-market reduction. Hence, the precomputed tests for manufacturing defects should be linked to the cores. There are new challenges [5] that must be tackled if onc applies core-based test. First, the description of all test-data aspects of the core such as test protocols, patterns, modes, ete. must be available. Second, there must be DPT techniques available that are suited for the core-based design style. Finally, test expansion of core-level tests into IC-level tests is required. The final goal is high fault coverage constrained with the least number of patterns and the least area for DFT.

Usually, the cores are embedded, i.e., the pins of the cores are not necessarily the IC pins. Thercfore, the boundaty-sean test standard can not be used directly for the core test resulting primarily from the access problem. The core-test standard [7] copes with the test-access mechanism using so called test-shells, which are wrapped around each core (Fig. 1), isolating in that way the core from the rest of the system. The inner part of the corc is labelled IP. The term "core" is now related to the IP equipped with the testshell.

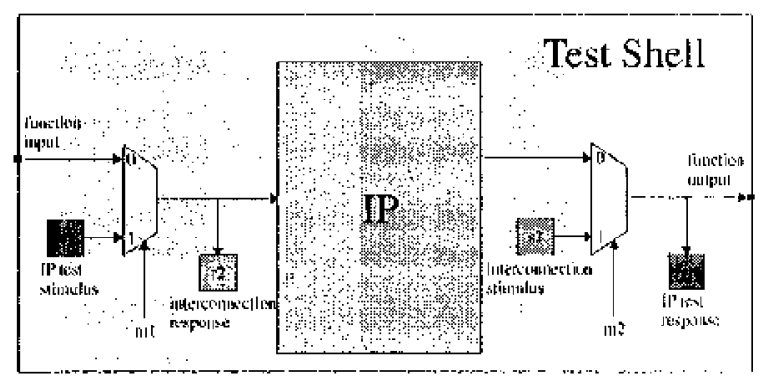

Fig. 1. The behavioural view of the test-shell

There are four basic modes of the test shell:

- Function Mode; this is for normal operation of the circuit, i.e., the test shell is transparent. 
IP test mode; the IP surrounded with this test shell is now being tested. The test-shell ensures that the test stimuli coming from the IC inputs are transported to the IP module under test and vice versa, i.e., that the test responses are transported from the IP module to the IC outputs.

- Interconnect test mode; in this case, the intercontections and the glue logic between the cores are cested. The test stimuli from the IC level for the intcrconnection logic succeding the outputs of the core are brought via the test shell: On the other hand, the test responses that come from interconnection logic in front of the inputs of the test-shell are captured and transported to the IC level.

- Bypass mode; now, the test stimuli for the other cores are transported via the test-shell.

The previously described modes are applied to the teststiell only, and they do not depend on any test mode of the IP surrounded with that test-shell.

Following the above trawing and cxplanations, it is obvious that the test-shell consists of flip-flops connected into scan chains, multiplexers and some logic. Of course, the actual implementation of the test-shell is flexibic and depends on the optimisation of the area and throughput. The test-shell modes are controlled via a standardised testcontrol mechanism (TCM). More details regarding the core-test can be found int [7].

\section{III, BASIC CORE TEST STRATEGY}

The result of the test pattern generation for a core has to be straightrorward in order to simplify the usage for the core user ("plug and play"). The tost-data access circuitries expressed as the test-shells enable the execution of these test patterns, with respect to the core under test. The DfT circuitries from the test sicll that are used to isolate inputs, outputs and input/output pins of the cores are shown in Figs, 2, 3 and 4 respectivoly [8].

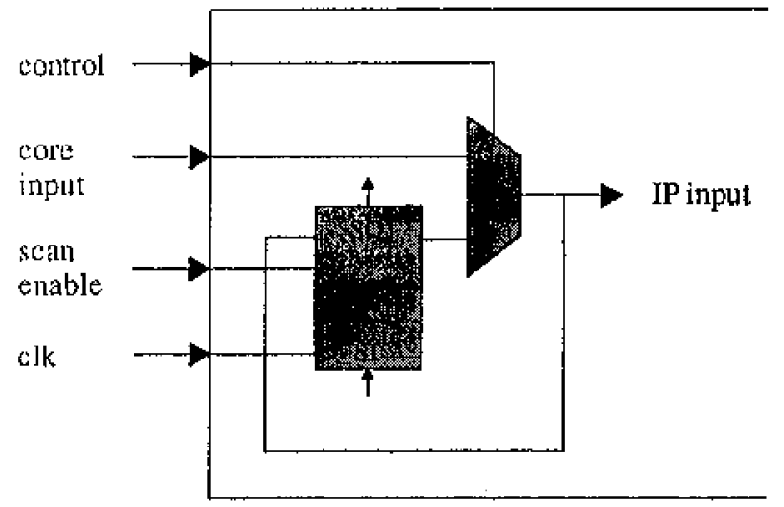

Fig. 2. The DfT inpui structure

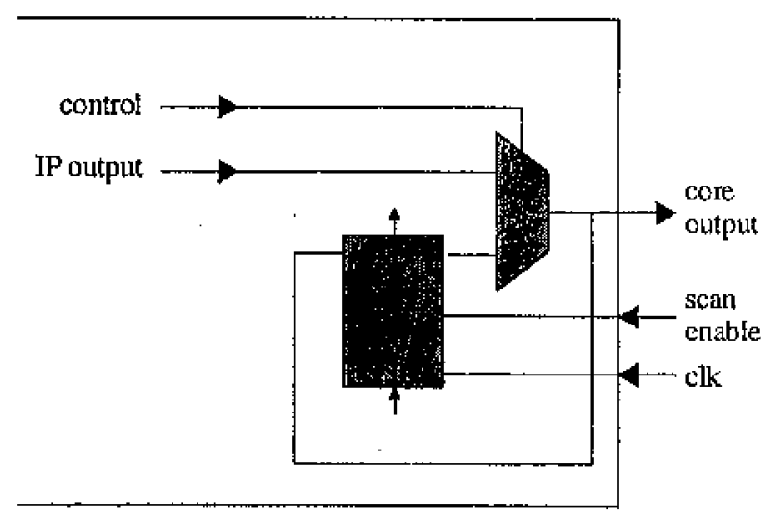

Fig. 3. The DFT output structure

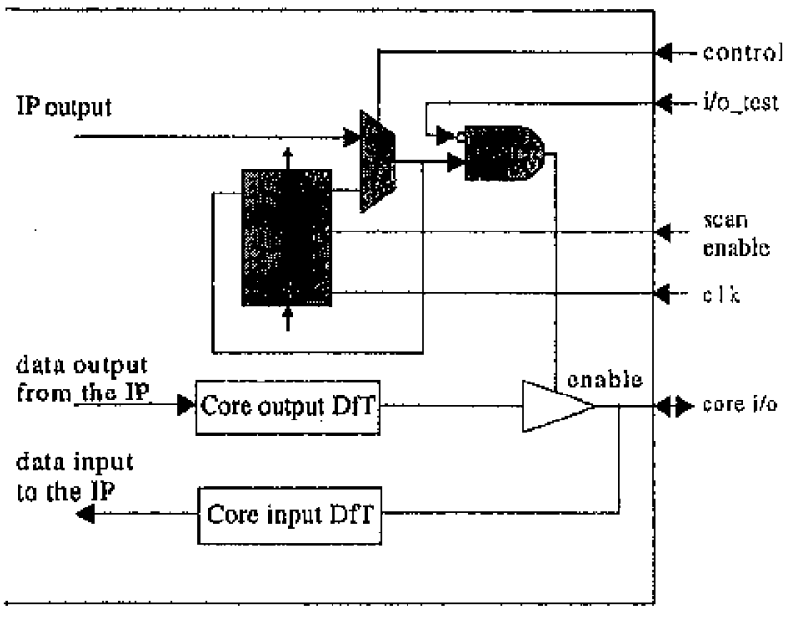

Fig. 4. The DFT circuitry for J/O isolation

The additional logic in Fig. 4 is neecssary since during the IP-test mode, the on-chip bus must not influence the cores. This is provided with the j/o_test signal forcing the tristate buffer into $\mathrm{Z}$-state.

The flip-flops in the above circuitrics are connected into scan chains and they can be used for test-stimuli application or test-response capturing. The used DfT structures remind on the circuitries from the boundary-scan technique [9]. Nevertheless, there is strong difference between them because of the two reasons. First, the coretest verifies the interconnections between the cores as well as their internals. Second, the number of extra pins on the boundaries of the cores is not limited as is in the case of the boundary-scan standard. The cores are still to be designed and one is free to use as many pins on the boundary of the core as required.

However, similar to the boundary-scan test where the chips are manufactured and tested, the cores must also come with generated test patterns resulting in accurate and high fanlt coverage. This is the task of the core provider, and hence the core user knows what to expect. 
The faul: coverage of the core is related to the fault coverage of the IP equipped with the test shell. However, onc is not free to generate the test patterns and calculate the fault coverage by simply running the ATPG on the core. The reason for this is that the cotes are embedded and the tcst-shells around the corcs have different modes with forced values on input pins. Therefore, it is necessary to split the ATPG run according to the different test-shell modes. The lest generation for the inner part of the core ([l) wili be carried out when the test-shell has a controliced value set for the IP-test mode. IP test patterns will not cover the faults in the test-shell and glue logic. These faults cen be detected during the interconnect test. Hence, another ATPG run is required when the control signals of the testshell are fixed for the inlerconnection test mode. Of course, the intercomections between the cores and glue logic are minor part of the design and they will require fewer test patterns compared to the IP test. The actual test patterns and exact fauit coverage of the embedded core will be then abcained by combining these two patterns.

'The core-based test generation flow that results in the core patcross and determines the real fault coverage for any environthent in which the core can be cmbedded is shown [10], [11] in Fig. 5. The llow proposed in this paper is in full agrement with the CTAG standard. All CAT tools in this tlow ate developed with features to ease the core-based test flow. Hence, the flow is highly automated.

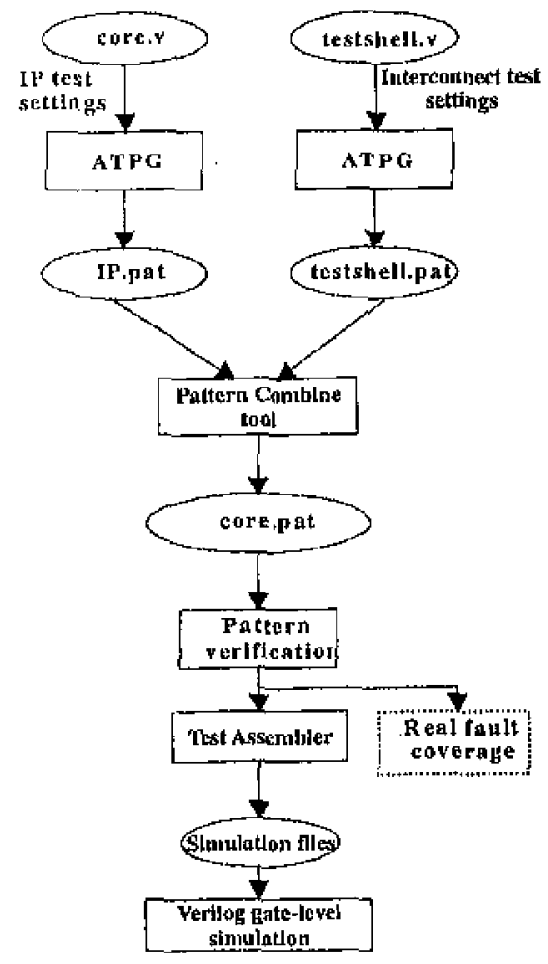

Fig. 5. The new proposed Computer-aided-test flow [10], [11]
This flow can be regarded in the following way. The "core. $v$ " and "testshell. $v^{\prime}$ are scannable netlists of the core and test-shell netlist, respectively. According to the previous explanation, two $\triangle T P G$ runs are required in order to generate the test patterns for the IP and the test-shell, By combining them, one will obtain the patterns that can be used to test the complete core (Fig. 6).

ATPG nun for the IP $\quad$ netlist: top_level.v
ATPG run2 for the test shell netlist: testshell.y
Combine the two patterns

Fig. 6. Core test scheme

A pattern verification tool calculates the real lault coverage of the core by applying the patterns to the corc. A test assembler can subsequently generate simulator test benches for many simulators with both stimulj and response information.

The flow depieted in Fig. 5, carricd ont by the core provider, provides the core user with the test patterns and the fault coverage of cach core in the chip. The corc user now only has to expand the core test pattems and to implement the top-fevel infrastructure by the test-patem expansion tool [5].

\section{RESULTS}

The proposed CAT flow for the test-pattern generation and exact fault coverage calculations of the cores havc been applied to a Philips pilot IC project chip of which the main characteristics are shown in Table $I$.

TABLE I

\section{THE MAIN CHARACTERISTICS OF THE PLOT IC}

\begin{tabular}{|l|l|}
\hline process & $\mathrm{CMOS} 5 \mathrm{M}$ \\
\hline feature size & $0.35 \mu \mathrm{m}$ \\
\hline total die area & $50 \mathrm{~mm}^{2}$ \\
\hline number of cores & 8 \\
\hline complexity & $=20 \times 10^{6}$ transistors \\
\hline number of the test-patterns & 3500 \\
\hline size of the largest core & $21.4 \mathrm{~mm}^{2}$ \\
\hline size of the smallest core & $0.45 \mathrm{~mm}^{2}$ \\
\hline
\end{tabular}

The fault coverage of the cores varies between 98.5 and $99.94 \%$. The obtained results are much better as compared to a chip of similar complexily and futictionality as 
reported in [12] with the average fault coverage of $91 \%$ and more than 4000 patterns. Note that the number of test pitterns is obtained after simple addition of the test patterns of cach core. Hence, the test patterns have stili to be expanded and compressed. However, it will not increase the number of test patterns, since only the test-protocols will be changed, not the test data.

The DrT area overhead, another consiraint that has to be laken into account, was also quite low. It amounted to $7.7 \%$ of the tota' chip area $4.5 \%$ is due to the core internal DfT and $3.2 \%$ results to the test-shells around the core which is quite acceptable. It has been noticed during the design that the small sized cores require relatively larger area for DfT. This oceurs since the test shell has the most impact on a small core with many ports. The DfT area overhead for the snaliest core is $30.2 \%$ while the area overhead due to the test shell for the largest core was only $0.5 \%$. Tyerefore, further improvenent of the core test strategy will focus on redwing the DfT area overhead for the smaller cores. Of course, that reduction may not influence the already achicved efficiency in terms of the test patterns and fault coverage.

\section{CONCLUSION}

The basics of the core test proposed by Philips CTAG group is explained in this paper. The so-called test shell is introduced providing the infrastructure for the test and isolation ol cmbedded cores. The test of the ombedied core corisists of the test of the inner part of the core (IP tesi) and the test of its interconnection together with the test shell. The automatic test-pattern generation flow according to the core test has been proposed and implemented. It restlts in a cest pattern set and accurate fault coverage of the core that can be used in an arbitrary environment. The proposed flow has been used in the Philips pilot IC project. The obtained results with respect to the number of the test patterns and the fault coverage were better compared to another similar design that has been donc at the other place. Also, the total DfT area overhead was quite acceptable.

\section{ACKNOWLEDGEMEN'T}

The large part of this paper is the result of the practical work carried out within Philips Semiconductors, Eindhoven. The authors acknowledge the contributions of R. Arendsen, E. J. Marinissen, M. Lousberg and all employees of the Philips Semiconductors ASG/ESTC group.

\section{REFERENCES}

[1] R. Chandramouli, S. Pateras, "Testing Systoms on a Chip," IEEE' Spectrum, pages 42-47, November 1996.

[2] P. Varma, S. Bhatia, " $\Lambda$ Structurcd 'Test Re-Use Methodology for Systems on Silicon," Proc, of the I" IEEE Workshop on Testing Embedded Core-based Systems, Washington D.C, November 1997, paper 3.1.

[3] A. Jas, N. Touba, "Test Vector Decompression via Cyclical Scan Chains and its Application to Testing Core-Based Designs," Proc. Int. Test Conf., October 1998, Washington D.C, pages 458-467.

[4] F. Beenker, B. Bennetts, L. Thijssen, Testability Concepts for Digital $\mathrm{CC}^{\prime} \mathrm{s}$ - The Macro Test Approach, volume 3 of Fronfiers in Electronics Tesing, Kluwer Academic Publishers, Boston 1995.

[5] E,J, Marinissen, G.E.A.Lousberg, "Macro Test: A libera] Test Approach for Embedded Reusable Cores," Proc of the

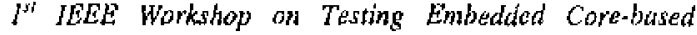
Systems, Washington D.C, November 1997, paper 1.2.

[6] IEEE P1500 Web Site, hitp://gouper,iece org/grougs/1.500/.

[7] E.J.Marifissen, R. Arendsen, G. Bos, H, Dhigemanse, $M$. Lousberg, C. Wonters, "A Structured and Scalable Mechanism for Test Access to Embedded Reusable Cores," Proc. Int. Test Conf., October 1998, Wasitington D.C, pages 284-293.

[8] R. Arendsen, M. Lousberg, "Core Based Test for a System on Chip Architecture Framework," Proc of the $2^{\text {nd }}$ IEEF Workhop on Testing Embedded Core-based System. Washinglon D.C., October 1998, paper 5.4.

[9] IEEE Computer Society, IEEE Standard Test Access Port and Boundary-Scan Architecure - IITEE Std 1149, 1 - 1990, IEER, New York, 1900

[10] Various authors, "Core-based Test: Cookbook," Philips Intemal publication, 1998.

[11] V.A. Zivkovic, R,G.J. Arendsen, "Accurate Fautl Coverage Determination in Core-based Test," ASG/ESTC98.7156, October 1998, Philips Internal Documentation.

[12] J. Saxena, P. Policke, K. Cyr, A. Benavtdes, H. Malpass, F, Ngoh, "Test Strategy for 'Tl's TMS320AV7100 Device," Proc. of the $2^{\text {nd }}$ IEEE Workshop on Testing Enbedded Corebased Systems, Washington D.C., October 1998, paper 32. 